\title{
SELF DEFENSE TRAINING FOR PROSPECTICE DOCTORS AND MEDICAL STAFF - OPPORTUNITIES AND ATTITUDES
}

\author{
Vladimir Ivanov \\ Medical University - Sofia (Bulgaria)
}

\begin{abstract}
Violence over doctors and medical staff is a serious social issue that has been neglected in modern society. Numerous attacks on emergency medical care workers and ward and office medical professionals have been witnessed in recent years, and in most cases these incidents were left without consequence or with occasional convictions. This survey aims to study the attitudes among the students of the Medical University of Sofia regarding the problem with aggression and violence against medical professionals and employees in the medical sector in Bulgaria and the opportunities that self-defence training at the Medical University gives. The study was carried out by means of applying the survey method with students who participated in the elective course (module) of Self-defense which was conducted during the second semester of 2020 - 2021 academic year. The conclusions that can be drawn, indicate that the participants are very well informed about the problem with aggression against medical professionals, and they consider poor organization in the healthcare sector as the main cause of the problem. Nevertheless, survey participants believe that incriminating aggressive behavior against medical staff is not going to bring the desired results against this kind of behavior. The attitude of the students who participated in the self-defense training sessions was extremely positive as they claim that this type of additional training could be the first step of future doctors to opposing aggression in the health-care sector.

Keywords: self-defense; Medical University of Sofia; aggression; healthcare; verbal violence; medical staff
\end{abstract}

\section{Introduction}

Society and medical care staff seem to overlook the problem of violence at the workplace. The importance of this problem is, to a great extent, underestimated and is included in the context of daily challenges that people face, such as the stress of negative consequences. (Hristov et al. 2001). One of the most precise definitions of violence in the workplace defines it as "acts of violence, including physical attack or the threat of such directed towards persons who are at work or in the act of performing 
their duties"1). According to the chairman of the Bulgarian Medical Association, 7\% of medical workers in the country have been subjects of direct physical violence ${ }^{2}$. Bulgarian Medical Association data shows another bothersome trend: more than $48 \%$ of medical workers have encountered verbal aggression. According to the latest data summary from the past three years, more than 330 cases of verbal violence and 41 cases of direct physical violence have been recorded in emergency medical centers, and 623 cases of violence have been recorded in emergency wards ${ }^{3}$, which is a rather alarming trend. According to the Association of Healthcare Professionals, emergency medical staff are attacked the most often and in second place come medical professionals who work in offices, including dental ones. To a large extent, prospective doctors and medical workers who are being trained by medical universities and at the Medical University of Sofia in particular, do not possess the knowledge and skills needed to perform this kind of self-defense. And also, it is very important, as it was described in the research of Iancheva, Rogleva-Domuschieva, Kuleva in 2018, that the need of security concerns a person's basic motivation. (Iancheva, Rogleva-Domuschieva, Kuleva 2018).

This gave us the grounds to prepare and deliver an elective course (module) on Self-defence in the format of additional training as prevention of aggression against future medical workers in the healthcare sector.

The curriculum of the course included:

- Theoretical sessions on the basics of Self-defence

- Legal advice regarding the framework of inevitable defence in which legislation allows the freedom of choosing the means of self-defence, as well as the limitations to such choices that legal acts and laws impose (Borisov 2020)

- Psychological aspects of aggression and violence, as well as maintaining selfcontrol in extreme situations.

- Acquiring the ability of making adequate decisions to cope and survive numerous daily challenges.

By means of demonstration methods from different martial arts, the practical part allowed the students to master some basic self-defence techniques:

- Kicks (low-level, middle-level, high-level)

- Punches (straight, left and right)

- Blocks

- Release from grips and applying some throws that can be performed in a real daily situation.

- Self-defense techniques against a variety of objects such as a knife or a gun.

- Practical demonstrations and learning self-defence against every-day situations including:

- an attempted rape

- an attempted purse rape

- sexual assault

- aggression in a vehicle 
In their research, Alexandrova, Penov, Petrov \& Zaykova 2018 conclude that the workloads in the circuit training model that they designed of higher levels than were the workloads at competitions, for this reason, we have reason to believe that this type of training and demonstration would give a high enough efficiency not only to get acquainted with the basic methods of specific strokes, but also to maintain good physical training of future medical professionals. (Alexandrova, Penov, Petrov \& Zaykova 2018)

Goals of the survey. The present survey aims to present the attitude of students towards the social problem of aggression and violence against medical workers in Bulgarian healthcare service and the result of the newly acquired knowledge and skills that the prospective medical workers have gained after their participation in the training in the elective course of self-defense at the Medical University of Sofia.

Study group. Organized Self-defense training was conducted by the Sports sector during the second semester of $2020-2021$ academic year. Thirty-five students of Medicine and Dental Medicine from first to fifth year from the Medical University of Sofia took part in the course.

Survey methodology. The study methodology employed an online anonymous survey method in two parts. The answers of 17 women and 13 men aged from 19 to 23 were analysed regarding the following:

- violence against the person and aggression against medical workers as a social problem and its causes as well as the efficiency of the measures that the state took against it in the area of healthcare;

- the efficiency of training and the opportunities provided by the elective course in Self-defence taught at the Medical University of Sofia.

\section{Results}

The results' analysis shows that $97 \%$ of the participants are well informed about the social problem related to aggression and violence against medical workers in the healthcare system of Bulgaria. (Figure 1)

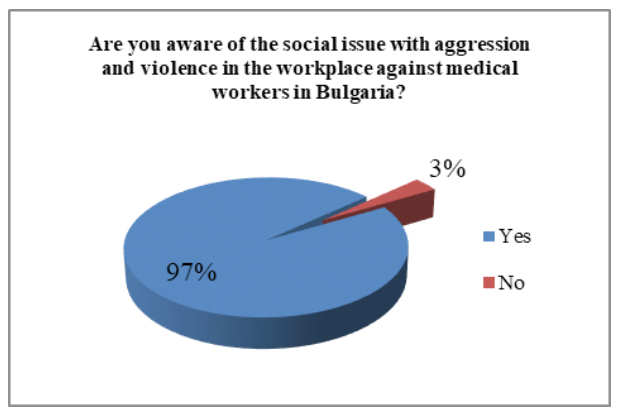

Figure 1. Answers about the awareness of the problem with the aggression and violence

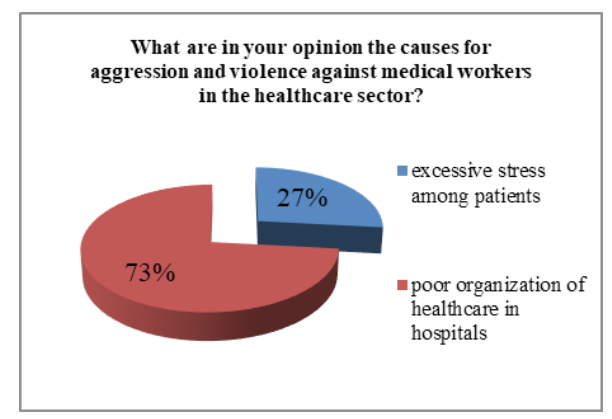

Figure 2. Answers about the causes for aggression and violence in the healthcare sector 
A large part of them, $73 \%$, claim that the reason for the problem with violence against medical workers is the poor organization of healthcare services in hospitals, while $23 \%$ believe that the overwhelming stress experienced by the patients is the cause for the alarming statistics. (Figure 2)

Aggression and violence against the individual in society is condemned by $93 \%$ of all respondents, as this type of behavior is considered unacceptable in modern society and calls for legal regulations application. (Figure 3)

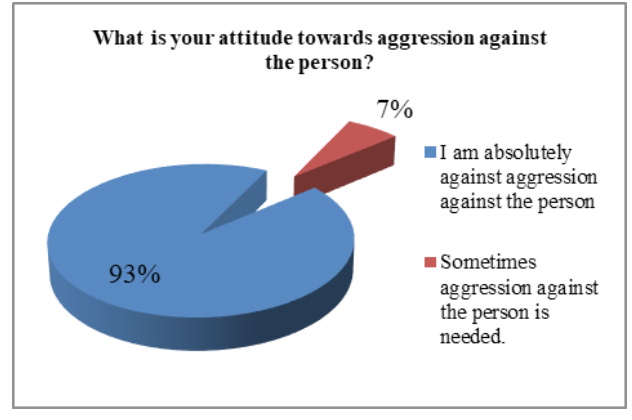

Figure 3. Answers about the attitude towards aggression

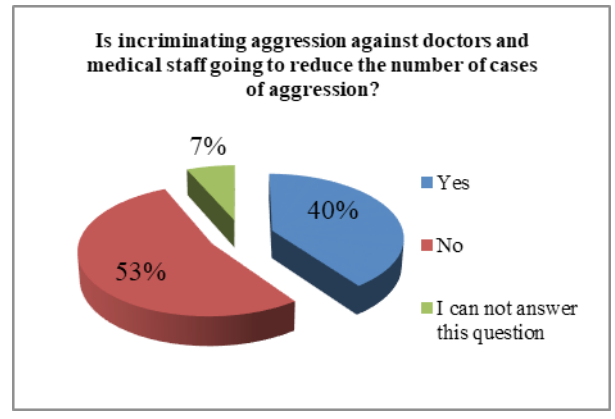

Figure 4. Opinion of the participants regarding the incrimination of the aggression against medical specialists

$53 \%$ of the students' answers reveal the fact that even if violence against medical workers were incriminated by law, this would not lead to a reduction in the number of cases of violence in the healthcare system, yet $40 \%$ of the respondents believe that putting aggressive behavior within the legal framework may reduce this antisocial behavior. (Figure 4)

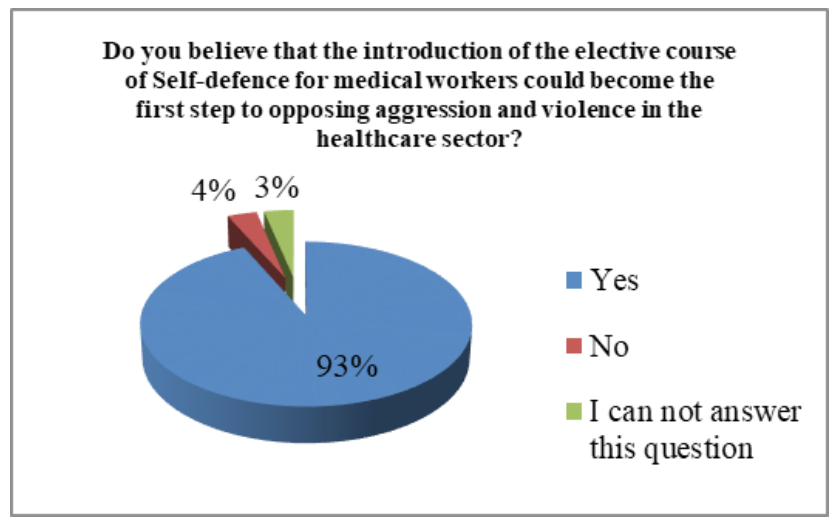

Figure 5. Opinion of the participants about the elective course of Selfdefense 
There is a positive trend according to which $93 \%$ of the students interviewed believe that including the elective course (module) of Self-defence as additional training in the Medical University of Sofia could be one of the first steps of tackling aggression against doctors and medical staff. (Figure 5)

\section{Training Results}

Upon completion of the course, $87 \%$ of the students believe that they received sufficient self-defense knowledge and skills in case they are subjected to violence at the workplace or outside it (Figure 6), and more than 94\% rank as very good or excellent the additional training they received at the university. (Figure 7)

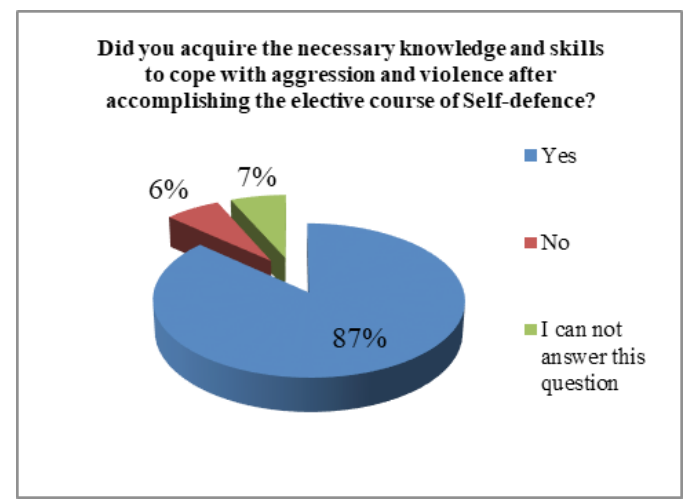

Figure 6. Opinion of the participants about the acquired knowledge and skills from the course

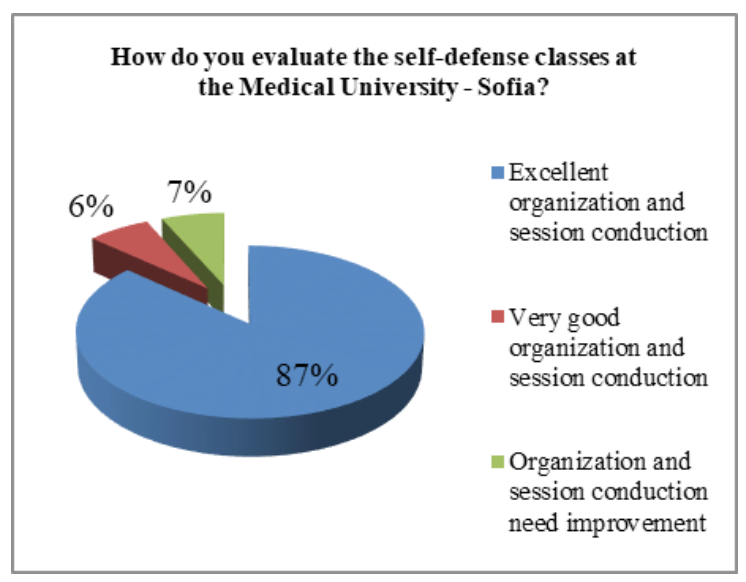

Figure 7. Evaluation of the self-defense course 
Trainees rank the theoretical part of the elective course of Self-defence which was conducted outline by means of the Google platform by giving it $91 \%$ for contents and $86 \%$ for visualization.

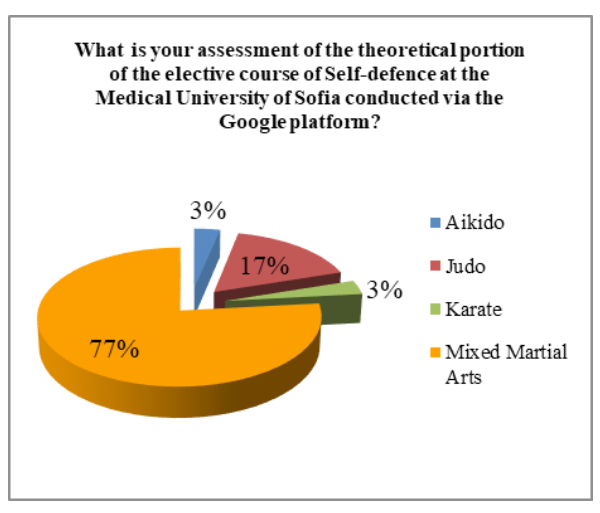

Figure 8. Opinion of the participants about the distribution of the parts in the course

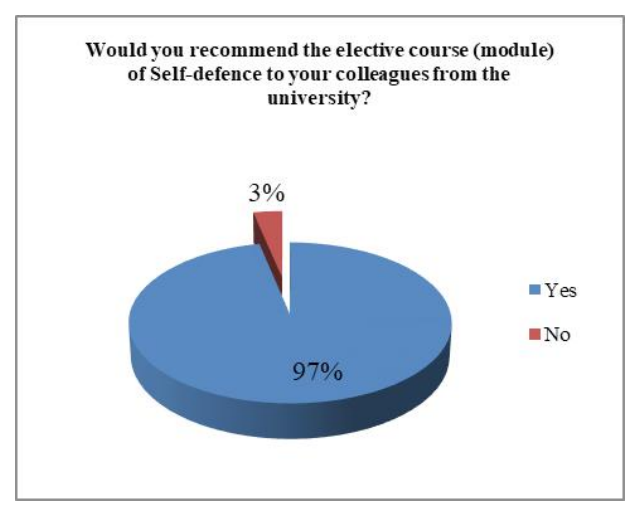

Figure 9 Recommendation of the course

According to $77 \%$ of the trainees, Mixed Martial Arts are among the most suitable self-defense sports and in order to improve the organization of the practical component, they should be included in the demonstrations during training. (Figure 8)

The attitudes of prospective doctors and medical workers interviewed regarding the development and implementation of such additional training organized by the Sports sector at the Medical University of Sofia are extremely positive and $97 \%$ would recommend that colleagues attend the electric module of Self-defence. (Figure 9). This indicates that young people are willing to confront modern social problems such as violence and aggression in society and in the specialty of their choice within the sector of healthcare in Bulgaria.

\section{Discussion and conclusion}

The following conclusions can be drawn after analyzing the responses of the students who participated in the survey:

1. The problem with violence against medical workers in the healthcare system is very serious, but it has not been fully recognized and is not yet being approached with the determination needed.

2. Even if aggressive behavior against medical workers were incriminated, to a large extent this would not produce the desired results due to the inability of 
healthcare workers to cope in critical situations and the fact that they are completely unprotected in smaller towns.

3. Preventive measures and measures for security and control.

4. The introduction of the elective course (module) of Self-defense as an additional course in the curriculum of the Medical University of Sofia (and possibly in other medical universities in the country) may become one of the initial steps of acquiring skills and knowledge to cope with aggression against doctors and medical staff.

5. After the training conducted, students have positive attitudes and consider as beneficial the knowledge they gained in the subject of Self-defense taught at the Medical University of Sofia. The majority share the opinion that more practical exercise and additional demonstrations of Mixed Martial Arts need to be included. Theoretical discussion themes, theoretical self-assessments and final grade need to be included as well.

\section{NOTES}

1. Cdc.gov. 2021. Occupational Violence | NIOSH | CDC. [online] Available at: $<$ https://www.cdc.gov/niosh/topics/violence/default.html $>$ [Accessed 22 May 2021].

2. Malasheva, M. 2020. Balgarskiyat lekarski sayuz s natsionalna kampania sreshtu nasilieto nad meditsi. [Online Video]. 1 September 2020. Available from: https://nova.bg/news/view/2020/09/01/298076/българският-лекарски-сьюзс-национална-кампания-срещу-насилието-над-медици/. [Accessed: 20 Мау 2021].

3. NOVA TV - News. (2020). Prokuraturata, MZ i BLS - zaedno sreshtu nasilieto nad meditsi. [Online Video]. 14 January 2020. Available from: https://nova.bg/ news/view/2020/01/14/274726/прокуратурата-мз-и-блс-заедно-срещу-насилието-над-медици. [Accessed: 20 May 2021].

\section{REFERENCES}

Alexandrova, A., Penov, R., Petrov, L. and Zaykova, D., 2018. Functional Characteristics Of Specialized Circuit Training For Karate Competitors. Journal of Applied Sports Sciences, (2) [December], 3 - 11. Borisov, I., 2020. Zashtita ot posyagatelystva, sopryazhennogo s nasiliem, ne opasnum dlya zhizni, libo s ugrozoy ego primenenia. [online] Molodoy ucheny. 4(294). 345 - 347 [In Russian] Available at: https:// moluch.ru/archive/294/66738/ [Accessed 22 June 2021].

Hristov, Zh., Tomev, L., Kircheva, D., Daskalova N., Mihaylova, T., Ivanova, V. \& Naidenova, Z., 2001. Workplace Violence in Healthcare in Bulgaria. Sofia: Institute for Social and Trade Union Research of KNSB 
- International Organization of Labor, Available at: http://knsb-bg.org/ pdf/case--bulg-f-za\%20pechat.pdf, [date of access: 21.05.2021].

Iancheva, T., Domuschieva-Rogleva, G. \& Kuleva, M., 2018. Sensation Seeking and Stress Coping Strategies of Participants in Military Missions in Afghanistan and Antarctic Expeditions. Journal of Applied Sports Sciences, (1) [July], $53-63$.

\author{
$\triangle$ Vladimir Ivanov \\ https://orcid.org/0000-0001-9634-2483 \\ DEOS, Section Sport \\ Medical University - Sofia \\ 2, Zdrave St. \\ Sofia, Bulgaria \\ E-mail: v.ivanov@deos.mu-sofia.bg
}

